\title{
Children's learning about water in a museum and in the classroom
}

\author{
Harriet R. Tenenbaum ${ }^{\mathrm{a}, *}$, Gabrielle Rappolt-Schlichtmann ${ }^{\mathrm{b}}$, \\ Virginia Vogel Zanger ${ }^{\mathrm{c}}$ \\ a Psychology Department, Brooklyn College, CUNY, 2900 Bedford Avenue, Brooklyn, NY 11210, USA \\ ${ }^{\mathrm{b}}$ Harvard University Graduate School of Education, Appian Way, Cambridge, MA 02138, USA \\ ' The Children's Museum, 300 Congress Street, Boston, MA 02210, USA
}

\begin{abstract}
This study investigated the effectiveness of a combined museum and classroom intervention project on science learning in low-income children. The focus of the program was on children's content knowledge and concept complexity. Thirty children were in the experimental group. A control group of 18 children visited literacy and social studies exhibits at the museum. Results indicate that children in the experimental group learned content knowledge about the components of bubbles and the definition of a current. Although children in the experimental group exhibited more complex concepts about buoyancy, they did not become more correct in their judgments. In general, the program supported children's science literacy development with regard to both concept complexity and content knowledge. Results are interpreted in relation to socio-cultural and constructivist frameworks from developmental psychology.
\end{abstract}

(C) 2004 Elsevier Inc. All rights reserved.

Keywords: Children; Museum; Classroom

\section{Introduction}

The National Science Foundation suggests that adults must be familiar with basic science concepts for employment today. Unfortunately, African-American, Latino/a, and low-income European-American students lag behind other students in National Assessment of Educational Progress (NAEP) science assessment tests in the fourth, eighth, and twelfth grades (NSF, 2000). Additionally, African-American and

\footnotetext{
* Corresponding author. Tel.: +1-718-951-5872.

E-mail address: HarrietT@brooklyn.cuny.edu (H.R. Tenenbaum).
} 
Latino/a students tend to take fewer science courses than European-American students (NSF, 2000). ${ }^{1}$ By failing to educate and engage these students in science, the United States may not be able to remain competitive internationally (NSF, 2000). The following study investigates a program designed to engage low-income kindergartners from diverse ethnic backgrounds in science and improve their content knowledge and basic understanding of water related concepts.

\subsection{Science learning and achievement}

In general, students' science enjoyment has been shown to decrease as they progress through school (Yager \& Yager, 1985). This decrease is of concern because students' enjoyment of and motivation for science learning has been linked to achievement in science (Welch, Walberg, \& Fraser, 1986). Science enjoyment in African-American children also decreases. Atwater, Wiggins, and Gardner (1995) found that fewer than $25 \%$ of inner-city African-American middle school students had positive attitudes toward science. In contrast, although less affluent African-American children had less knowledge about science, they desired more science instruction compared to their more affluent European-American peers (Wenner, 2003). To educate adequately African-American children for today's marketplace, educators need to focus on ways to improve these children's science knowledge and attitudes.

Unfortunately, classrooms attended by low-income students tend to rely simply on giving instructions, information, and tests rather than good teaching (Harbeman, 1991). While reinforcing the internalization of rote science facts is important in this era of high stakes testing, this approach without concurrent support for students in their quest to develop their own concepts and explanations about science is not good instruction (Chapman, 2000). As a result, the pedagogy of poverty may contribute to the decline of science interest and learning within these populations. To increase students' science enjoyment, some researchers have suggested integrating hands-on real world activities into the curriculum (Baker \& Learing, 1995; Brown, Metz, \& Campione, 1996; Martinez, 1992; Paris, Yambor, \& Packard, 1998). Harbeman (1991) similarly suggests that good teaching is found when children are actively involved, enjoy their classroom learning, and participate in real-world experiences, such as visiting museums.

\subsection{Museum learning}

Museums may be a particularly good context to involve young children in positive everyday hands-on science because museums support children's intrinsic motivation while creating a rich learning context (Ramey-Gassert \& Walberg, 1994). Yet, merely placing a student in a science museum context without appropriate support and guidance is unlikely to produce the desired result.

Specifically, recent research suggests that to support optimal learning, museum programs should guide children's exploration (Gelman, Massey, \& McManus, 1991). For example, in a seminal study, Paris et al. (1998) focused on a 6-week museum-school partnership with students in third, fourth and fifth grades around the topic of biology. This innovative program combined individual learning with appropriate guidance. Students completed individualized projects and held a family science night. The authors reported more positive student science affect after participation in the program. Additionally, students'

\footnotetext{
${ }^{1}$ NSF (2000) does not report comparable data for low-income European-American students. Given that low-income students score lower than their high-income peers in the twelfth grade, we assume that European-Americans from low-income backgrounds have probably taken fewer courses in science and are underrepresented in the science and engineering labor force.
} 
problem-solving skills increased. Furthermore, anecdotal evidence suggested that students enjoyed the curriculum unit and visits to the museum. In sum, a carefully developed museum program may increase children's learning and attitudes toward science.

Despite the work of Paris, Yambor and Packard, few studies have examined integrated classroom and museum learning, and fewer have employed assessment techniques that enable the examination of both children's concept development and content knowledge within the domain of science. The present study is distinct from prior studies of classroom and museum studies in three primary ways. First, studies have tended to focus on students in the third grade and older (e.g., Paris et al., 1998). In contrast, the present study investigates kindergarten students. Second, we employ a framework for assessing children's concepts that incorporates both the constructivist and socio-cultural traditions from developmental psychology. This approach directly reflects the museum and school's curricular emphasis on learning in multiple contexts with support. Moreover, it allowed us to assess the complexity of participants' concepts in context without regard to correctness-two dimensions of learning rarely studied simultaneously (e.g., Marek, Boram, Laubach, \& Gerber, 2002). Finally, we focus on low-income, inner-city children from diverse ethnic backgrounds and include a control group composed of children from a similar background. The majority of research on children's science learning in museums has focused on children from middle-income, European-American backgrounds. Our research may shed light on ways to involve ethnic minority children from low-income backgrounds in science learning.

\subsection{A framework for learning and development in context}

Combining guidance with hands-on learning, the present intervention attempts to utilize both the socio-cultural and constructivist perspectives that originated with Vygotsky and Piaget, respectively. While both of these theorists believed that interaction with the environment is necessary for the construction of knowledge in children's development (Piaget, 1983; Vygotsky, 1978), psychology has often characterized these theorists' perspectives as being in opposition to each other. Certainly, Piaget's emphasis on the interaction between child and object (child as scientist) and the construction of new knowledge through predictable stages in logical thought therein, is distinct from Vygotsky's emphasis on the interaction between child and object as socially mediated by a more advanced individual (child as apprentice). However, a large literature now documents that both Vygotsky's focus on the role of social support and Piaget's focus on the construction of new knowledge through predictable stages in logical thought play key roles in learning and development (Brown et al., 1996; Inhelder \& Piaget, 1958; Rogoff, 1990; Vygotsky, 1978; Wertsch, 1991). To assess children's understanding accurately, a compromise between the socio-cultural and the structure-as-form formal stage approach must be made through their similarities and complementary nature (Fischer \& Bidell, 1998).

One theory that has been proposed as a compromise between formal stage theory and the socio-cultural approach is Fischer's skill theory. Fischer and Bidell (1998) asserts that individuals have skills that enable them to act in organized ways in specific contexts. Skills are constructed gradually though practice in real activities during interaction with others and independently (Fischer \& Granott, 1995); an individual may develop a skill to ride a bike, understand metaphor, or perform algebraic operations. Skills are domain specific in that there is a high degree of variability across tasks and contexts. However, skill theory allows for developmental synchrony across skills as well (Fischer \& Bidell, 1998). Under optimal performance conditions, a developmental spurt may be noted for many skills across domains marking a transition. For 
example, there may be a spurt between representational and abstract thought (Fischer \& Bidell, 1998). Optimal performance can be elicited under the guidance of a teacher or mentor. With emphasis on the social nature of the construction of new understanding, skill theory represents a more complete picture of children's learning, allowing for both synchrony and variability in development. From this perspective, appropriate interaction with teachers and others within museum and classroom contexts would help children to develop and maintain new science concepts.

\subsection{Content knowledge about bubbles and currents}

Little research has been conducted on children's understanding of bubbles and currents. The questions regarding these topics were exploratory. We expected that children's content knowledge about these topics would increase after visiting the science exhibits. Although an increase in content knowledge about currents and bubbles may not reflect conceptual development on these topics, such an effect would be noteworthy. Specifically, in this era of standardized testing, children as early as pre-kindergarten are expected to be accountable for basic content knowledge in science to progress successfully through school (e.g., Massachusetts Department of Education, 2001). Moreover, researchers have suggested that reading comprehension for science is aided when children have sufficient scientific vocabulary to decode scientific text (Meyerson, Ford, Jones, \& Wood, 1991). Thus, the identification of an integrated curriculum that supports an increase in children's knowledge of science content is desirable.

\subsection{Conceptual development about buoyancy}

To assess the effect of this multi context high support curricular design on participants' concepts about buoyancy accurately, we employ a skill theory approach. This approach allowed us directly to assess the complexity of participants' concepts in context without regard to correctness. We predicted that after visiting the science exhibits children would demonstrate more complex concepts about why objects sink and float and make more correct judgments about whether objects would sink or float.

\subsubsection{Previous research on children's concepts about buoyancy}

Beginning with Piaget, there has been much research devoted to the topic of buoyancy and density. Piaget (1930/1960) argued that children go through four primary levels in their explanations of an object's buoyancy. In the first level, children's explanations do not correspond with their observations. Instead, children appeal to moral reasons as to why things float. During level two, children's explanations are dependent on their observations. However, children tend to believe that an object might float because it is strong or heavy. Once children reach level three, they begin to use what Piaget termed dynamic reasons to justify their observations. For example, a child will appeal to how light an object is to account for why something floats. Finally, when children enter level three, they begin to consider both volume and weight in relation to liquid to explain why something sinks or floats. It is not until level four that children differentiate density and weight.

Many researchers have replicated and elaborated on Piaget's original findings. For example, Smith, Carey, and Weiser (1985) examined children's understanding of density in a cross-sectional study. They focused on children's differentiation of volume, size, and density. Children sorted blocks of varying sizes according to whether they were aluminum or steel. Most young children relied on felt weight while ignoring an object's size. Children between the ages of five and seven usually did not dif- 
ferentiate weight and density. By age eight and nine, the majority of children differentiated density from felt weight in their judgments. The authors argued that even young children indicated they had theories about volume, weight, and density. With regard to correctness, Kohn (1993) suggested that although children may not be able to integrate many of the dimensions involved in understanding density, young children demonstrate some knowledge of the related concept of buoyancy. When asked to make buoyancy judgments about aluminum- and wood-coated objects, 3-year-old children make correct predictions 53\% of the time. Improving slightly, 4- to 5-year-old children make correct predictions $72 \%$ of the time. In contrast, college students make correct predictions $86 \%$ of the time (Kohn, 1993).

To assess children's concepts about buoyancy and the effect of the intervention curriculum of focus here, we employed Fischer's skill theory. This approach offered three advantages, one conceptual and two technical. First, skill theory directly reflects the museum and school's curricular emphasis on learning in multiple contexts with support. Second, using skill theory allowed us to assess the complexity of participants' concepts in context without regard to correctness. Correctness and complexity are dimensions of learning that are assumed to operate in concert but are rarely studied simultaneously. Recent research in child development suggests that increases or decreases in correctness and complexity need not coincide (Dawson, 1999). Third, evidence now suggests that complexity of thought as assessed through Fischer's skill theory is in fact interval such that each level within the skill theory framework is ordered hierarchically and the distance between levels is consistent and meaningful (Dawson, 1999, 2002; Dawson \& Fischer, 2003; Dawson, Xie, \& Wilson, 2003).

\subsubsection{Applying a new framework for assessing children's concepts about buoyancy}

Given the participants' range of ages and building on the work of Piaget and others, we hypothesized that children's concepts about why objects sink or float would be in the representations range within Fischer's skill theory framework (Fischer \& Bidell, 1998). In the strictest sense a representation is something held as a symbol or not exclusively tied to an external sensory motor action; for example, a representation is any word, picture, image or action that is symbolic (Hetherington \& Parke, 1993). Fischer asserts that symbolic thought emerges synchronously, across many domains, under optimal conditions between 18 and 24 months of age in the form of single representations. At this level children's thought or skills in particular domains are largely definitional; the object is light, it floats. Representational mappings is the next level, emerging under optimal conditions between 3.5 and 4.5 years of age. Here children coordinate two or more representations or attributes of the object under a single concept; the object floats because it is light and small. Finally, representational systems emerge under optimal conditions between 6 and 7 years of age. This level is characterized by the coordination of two or more representational mappings into a system of representations; the object floats because it is light for its size in the water. The age estimates for the emergence of each of these levels of complexity in thought are approximate. Most studies informing these approximations have been conducted with middle-income European-American or European children and never in the domain studied here (Fischer \& Bidell, 1998).

It is likely that young children have some knowledge of buoyancy and density but not complete mastery. Thus, we expected improvement in the complexity of children's buoyancy understanding after participation in the integrated museum and science curriculum. Given that participants were between 5 and 6 years old, we expected their concept complexity during both the pre and post test to be within the representations range of Fischer's skill framework. 


\subsection{Attitudes about science}

Additionally, many have suggested that in addition to learning content, children need to have positive attitudes toward science for learning to occur (Weaver, 1998). We predicted that after visiting the science exhibits children would become more positive in their attitudes toward science. Engaging in hands-on science in integrated museum and classroom collaborations has been shown to increase children's enjoyment of science topics (Paris et al., 1998). Moreover, working with others and using more appealing materials has been found to increase children's science interest (Martinez, 1992). The identification of an integrated curriculum that supports positive attitudes toward science is especially important with low income and minority populations given these populations' noted low interest and participation in science (NSF, 2000) and the often reported link between enjoyment of and achievement in science (Welch et al., 1986).

\subsection{Assessing children's learning and affect regarding water}

The purpose of this study was to test the effects of the combined museum and classroom intervention program targeted at teaching concepts and content knowledge about water to low-income kindergartners described above. Specifically, we hypothesized that after being assigned to an integrated museum and classroom science curriculum children would: (1) become more knowledgeable about the components of bubbles and the definition of a current, (2) demonstrate more positive affect about science, (3) demonstrate more complex concepts about why objects sink and float, and (4) make more correct judgments about whether objects would sink or float.

\section{Method}

\subsection{Overview}

This study reports on a museum-school partnership. The ongoing museum-classroom curriculum focuses on hands-on activities in the classroom and the museum, which enables kindergarten teachers to implement the state learning standards. The topics were focused around science, social studies, and literacy. As part of this collaboration, 161 kindergarten classrooms from one school district participated in a fieldtrip to a local children's museum. Prior to the fieldtrip, teachers conducted a lesson related to the content area of the exhibits. Forty-eight percent of the classrooms visited science exhibits, $37 \%$ visited social studies exhibits, and $15 \%$ visited literacy exhibits. Six classrooms were studied to examine the benefits of the program. Because the focus of this study is on science learning, the experimental group (three classrooms) visited three science exhibits and participated in two classroom lessons on water. The control group (three classrooms) visited social studies or literacy and participated in two classroom lessons related to social studies or literacy. All children were interviewed individually before and after participating in the lessons and visiting the museum.

\subsection{Participants}

The sample consisted of 48 kindergarten children in six different classrooms who attended public schools in a large northeastern city. Eighty-two percent of the children were African-American or 
Haitian-American, 12\% were European-American, and 6\% were Latino/a. Individual information was unavailable. However, district level information indicated that $72 \%$ of children enrolled in the public schools in this city were eligible for free or reduced lunch. Thirty children from three classrooms participated in the experimental groups, and 18 children from three other classrooms served as the control group. Each experimental classroom was matched with a classroom that was in the same school. The experimental classrooms visited science exhibits, whereas the other classrooms visited literacy or social studies exhibits. Nine girls and nine boys were interviewed from the experimental classes, and 12 girls and 18 boys were interviewed from the other classrooms.

\subsection{Procedure}

Teachers sent consent forms to families of children in the six classrooms. Children who returned consent forms were included in the study. Three children were absent when the interviewer visited their classroom. The response rate for children in the experimental classroom was $46 \%$.

\subsubsection{Pretest}

2.3.1.1. Science questions. Prior to visiting the museum and participation in the classroom activities, all children were interviewed individually by the first author. Interviews lasted approximately $10 \mathrm{~min}$ and were conducted outside children's classrooms. Children were questioned about the three content areas: buoyancy, bubbles, and currents. For the buoyancy content, children were asked to predict whether a ball, 4 different blocks, an empty bottle, an eraser, and a magnet would sink or float. Next, children were asked to justify the reasoning behind their buoyancy predictions. Finally, the children tested their prediction by placing the object into a bucket of water. To assess bubble knowledge, children were asked to list the ingredients in a bubble. The interviewer asked children to define a current. The order of the content areas (buoyancy, bubbles, and currents) was counter-balanced.

2.3.1.2. Affective questions. Using pictures of happy and sad faces, children were asked how much they enjoyed science on a scale of one to three. Children pointed to either a sad, neutral, or happy face. Children's answers were rated on a 3 -point scale $(1=$ sad, $2=$ neutral, $3=$ happy $)$.

The science and affective questions were counterbalanced. Interviews were audiotaped and transcribed.

\subsubsection{Lessons}

A cadre of teachers developed two lessons around each of the three exhibits that the classrooms visited. The lessons were created to teach the state curriculum standards, which were focused on teaching prediction and hypothesis testing skills. The majority of the teachers conducted two lessons with their students. These lessons were designed around bubbles, currents, and buoyancy. The lessons were delivered in whole-group format. The lessons are described below. Teachers involved in the experimental group in the present study conducted at least one water lesson prior to visiting the museum and one after visiting the museum. As reported by teachers, all lessons were conducted as a whole-group activity. The authors of this paper did not observe the classroom lessons.

2.3.2.1. Buoyancy. The first activity involved students filling a milk carton with increasing numbers of sandbags until it sank. Children were seated as a group around a water table and each child was given his or her own milk cartoon. Children guessed how many sandbags it would take to make the carton sink and 
then each added one sandbag at a time to his or her carton. During the second activity, students predicted whether objects would sink or float and justified their reasoning. The teacher would hold up an object and ask students to predict whether an object would sink or float and then to explain why. Placing it in the water, the teacher then demonstrated what happens. The teacher did not explain why the objects sank or floated.

2.3.2.2. Bubbles. There were two bubble activities. For the first activity, students tried to make bigger bubbles by blowing more air into a straw. Each child was placed in front of pan containing soapy water and was instructed to make a bubble. Before starting the lesson, children were asked to predict how big of a bubble they could make before it popped. The second activity involved mixing soap and water. Next, students made shapes with pipe cleaners and blew bubbles. Each child verbally predicted the shape of their bubble before blowing it. At the end of the lesson, children were simply taught that all bubbles not in containers are round.

2.3.2.3. Currents. The first activity had students explore the movement of water as they moved their hands in water. They were asked what direction the water would move if they moved their hands toward them and then away from them in the water. Children were told also that they were making "currents" and that a current is "what makes water move." Using a straw, students blew a ball across a water table during the second activity. Children worked together to make the ball move across the water table. They were explicitly taught that they were creating a current and were told the definition of a current as what "makes water move."

\subsubsection{Museum visit}

The control group visited either the literacy or social studies exhibits, which will not be discussed further. Each classroom assigned to science visited three science exhibits. The first author observed their trips. The three exhibits were buoyancy, bubbles, and currents. Children in each class were divided into two groups to form groups of 10-14 students. The observed lessons are described in the following sections.

2.3.3.1. Buoyancy. Directed by a staff person, each child experimented with his or her own jar. The following description comes from the field notes of the first author.

The staff person arranged children around a 10-foot replica of the Fort Point Channel while their teacher observed the students. Distributing an empty jar with a lid to each child, the staff person asked the children to predict whether the jar would sink or float in the water. Children raised their hands and three children gave predictions that the jar would float. The staff person encouraged the children to place their jars in the water at the count of 10 . As the children predicted, the jars floated. Children removed their jars from the water. The staff person asked children to predict how many marbles they needed to put into the water before the jars would sink. Each child made a verbal prediction ranging from two to 100. Each child was given 10 blue marbles to put in their jars. Children carefully placed the marbles in their jars and then closed the lids of the jars. Again, the staff person asked children to predict whether the jar would sink or float. She called on three children to give predictions, which were mixed. One child said that the jars would sink, whereas two children predicted that the jars would float. After returning the lid to the jar, children gently placed their jars on the water to watch them float on the count of 10 . Amidst cries of "I told you so" and disappointment, children removed their jars from the water. Next, children carefully added 10 more blue marbles for a total of 20 and sealed the their jars. Again, the 
children were asked whether the jars would sink or float. This time, two predicted that the jars would sink, and one predicted that the jars would float. With alacrity children placed their jars in the water to see them float one more time. When the docent instructed them, the children removed their jars and excitedly placed 10 more marbles into their jars. Again, predictions were mixed with two children saying that the jars would float, and one arguing it would sink. With rapt attention, children placed their jars into the water. The children cheered as the jars sank to the bottom of the channel replica. Finally, the staff person thanked the children for paying careful attention. While the staff person collected the jars, the teacher admonished the children to thank the staff person. Children lined up to visit the next science exhibit.

2.3.3.2. Bubbles. At the bubbles exhibit, a museum staff person engaged children in a lesson that lasted $5 \mathrm{~min}$ before they were allowed to play on their own. The description that follows comes from the first author's field notes.

Fourteen children were seated on the floor watching the staff person who led them through a series of questions about bubbles. Although children fidgeted on the floor, the children listened with rapt attention. The museum staff person welcomed the children to the museum and told them that she would teach them about bubbles. She asked children to list the main ingredients in bubbles. After reminding children to raise their hands, the staff person asked for one ingredient. The staff person pointed to Shaiwon and read his name off his name tag. Shaiwon answered that water was in bubbles. The staff person looked suitably impressed. Next, she called on Taylah to tell her another bubble ingredient to which Taylah replied, "soap." Finally, she called on Devon who told her that the third ingredient was "air." The staff person next questioned children about the shape of bubbles. She had children guess what shape a bubble that she was making with a square wand would be after she blew it. About half of the children guessed a square, and the other half guessed round. The staff person invited Kalonji to the front of the room to blow the bubble. The children seemed mesmerized. Finally, the guide asked children what made a bubble break. She called on three children who gave answers like, "your hand," "blowing too hard," and "you pop it." The guide explained that bubbles pop when someone or something touches a bubble. She then asked the students why the bubbles popped in this situation. A child responded that the bubble popped because something touched it. Another child agreed and added that the bubble juice got pushed away. Modeling how to make bubbles, the staff person carefully lowered a large wand into a shelf that had "bubble juice" (i.e., soap and water) in it. She then blew a very large bubble that floated over the children's heads only to pop on the ceiling. The children seemed excited. The staff person told the students that they would be allowed to play with the bubble exhibits, but that they had to cooperate and work together. On the count of 10, children darted over to different bubble stations. Although they were excited, children more or less cooperated. However, their cooperation was punctuated by the occasional "I got here first." The teacher and staff person intervened in these cases to convince children that they needed to wait their turn. Children were allowed to explore the exhibits on their own.

2.3.3.3. Currents. The currents exhibit consisted of a discussion about what a current was. Children collaboratively directed a stream of water toward a rubber duck and a ball to see which would flow through the channel more rapidly. The field notes of the first author is as follows.

Having visited the bubbles exhibit prior to the current exhibit, the children were slightly overexcited. Fourteen children lined up on either end of the replica of the Fort Point Channel. The staff per- 
son told the children that they would see what a current does. There were six jets of water on either side of the replica. Children were asked if they knew what a current was. Although these same children had been able to answer the questions about the ingredients of bubbles and had obviously been prepared by their teacher for their museum visit, not one child could answer the guide's question. I could not tell if they did not know or if they were overly excited at that point in their visit. Their teacher repeated the question until Essence answered, "it's what makes water move." The staff person held up a rubber duck and a rubber ball and asked children to predict which one would "swim" faster. The children shouted out their answers. The teacher gently reminded the children to raise their hands. The staff person asked the students to raise their hands if they thought the ball or the duck would go faster. The children seemed fairly evenly distributed in their opinions. The staff person instructed each child to stand behind a water jet and aim the jet toward the ball and duck as they raced down from the channel. She placed the two objects into the water and watched the children shoot the jets toward the end of the channel replica. As the ball beat the duck, about half of the children cheered. The staff person explained that a current, which they had created with the jets, is what makes things move in water. She asked them why the duck and ball moved. Phyllis answered that, "the water moved them."

\subsubsection{Post-test}

Within 2 weeks of their visit to the museum, children were re-interviewed by the first author. They were asked the same questions during the pre-test as during the post-test. The interviews followed the same order as the first interview that was conducted with the child.

One hundred twenty-three teachers also completed questionnaires reporting their overall opinions about the museum program. One question, about children's enjoyment at the museum, is of particular interest. Teachers responded on a Likert scale of 1 (disagree strongly) to 4 (strongly agree) whether children had fun at the museum.

\subsubsection{Coding}

2.3.5.1. Buoyancy. Children's answers to whether an object would sink or float was coded as correct, incorrect, or does not know.

Following skill theory, children's answers to why they thought that something would sink or float was coded on a continuum from the least complex to the most complex. Table 1 displays the coding scheme and provides samples of children's responses. Children's answers could range from the level of sensorimotor system to that of representational system. A sensorimotor system is when the child encoded the name of the object. A single representation is definitional in nature such that a single aspect of the object in question is identified; within the buoyancy domain a child exhibiting a single representation might note that an object sank because, "it is heavy." A representational mapping is more complex than a single representation because it coordinates two or more aspects of the object under a single concept; within the buoyancy domain a child exhibiting a representational mapping might note that an object "floats because it is heavy and large." Two previously unconnected single representations about the object (e.g., the object is heavy; the object is large) are coordinated by the concept of floating or being buoyant. A representational system is more complex than a representational mapping because it coordinates two or more concepts into a system of concepts; within the buoyancy domain a child exhibiting a representational system might note that an object "sank because it's heavy for its size in the water." Thus, a relatively simple representational mapping for density (i.e., heavy for its size) is coordinated with the child's 
Table 1

Coding for representation level of buoyancy understanding using skill theory

\begin{tabular}{|c|c|c|c|}
\hline Level & Code & Description & Example \\
\hline Sensorimotor systems & 1 & $\begin{array}{l}\text { The child encodes the identity of the object } \\
\text { rather than an attribute of the object }\end{array}$ & $\begin{array}{l}\text { "The magnet will sink because it is } \\
\text { a magnet" }\end{array}$ \\
\hline Single representation & 2 & The child notes one attribute of the object & $\begin{array}{l}\text { "The magnet will sink because it is } \\
\text { heavy" }\end{array}$ \\
\hline Representational mapping & 3 & $\begin{array}{l}\text { The child coordinates two attributes of the } \\
\text { object under the concept of sink or float }\end{array}$ & $\begin{array}{l}\text { "The magnet will sink because it is } \\
\text { big and heavy" }\end{array}$ \\
\hline $\begin{array}{l}\text { Representational transitional } \\
\text { mapping }\end{array}$ & 4 & $\begin{array}{l}\text { Coordinates two mappings: } \\
\text { (i) Rudimentary concept of density } \\
\text { coordinated with concept of buoyancy } \\
\text { OR } \\
\text { (ii) Representation(s) of the water and the } \\
\text { object coordinated by concept of } \\
\text { buoyancy }\end{array}$ & $\begin{array}{l}\text { (i) "The magnet will sink because it } \\
\text { is heavy for its size" } \\
\text { (ii) "The magnet will sink because } \\
\text { it is heavy for the water" }\end{array}$ \\
\hline Representational system & 5 & $\begin{array}{l}\text { Coordinates two or more representational } \\
\text { mappings under a single concept; } \\
\text { Rudimentary concept of object density } \\
\text { coordinated with representation(s) of the } \\
\text { water under single concept, buoyancy }\end{array}$ & $\begin{array}{l}\text { "The magnet will sink because it is } \\
\text { heavy for its size in the water" }\end{array}$ \\
\hline
\end{tabular}

representation(s) of the water into a system of representations by the concept of buoyancy. Based on their complexity, children's answers were given scores ranging from one (i.e., sensorimotor system) to five (i.e., system). When children did not answer or said that they did not know, they were given a score of zero for complexity.

2.3.5.2. Bubbles. The number of correct ingredients in a bubble was coded. Children's scores ranged from zero (i.e., if they did not know any of the ingredients in bubbles) to a score of three (e.g., air, soap, and water). Incorrect ingredients (e.g., spit) were ignored.

2.3.5.3. Currents. For the currents question, children were scored as correctly defining a current if they mentioned "making water move."

\subsubsection{Reliability}

The two authors met for $4 \mathrm{~h}$ for 2 weeks to train for reliability on the three different coding schemes. To test for inter-coder reliability, each coder independently coded 12 children's responses (25\% of the data set). Coders were blind to whether children were assigned to science or other exhibits. Reliability was evaluated using kappa coefficients. According to Fleiss (1981), kappa coefficients above 0.75 reflect excellent agreement. An overall kappa of 0.99 was obtained for the number of bubble ingredients children listed, 0.67 for whether children knew what a current was, 0.82 for the level for the buoyancy question, and 0.79 for whether children were correct in predicting whether an object would sink or float. 


\section{Results}

\subsection{Data reduction}

To examine the level of children's justifications of why objects would sink or float, an arithmetic mean was calculated for the eight different objects. This mean was computed separately for children's replies before and after they visited the museum. In addition, an arithmetic mean was calculated for the number of times children made correct or incorrect predictions.

\subsection{Preliminary analyses}

Across the eight objects, children were scored at level of 1.73 (S.D. $=0.56$ ) before visiting the museum and engaging in the pre- and post-visit activities, and at a level of 1.85 (S.D. $=0.45$ ) after visiting the museum. Children listed a mean of 1.12 (S.D. $=0.86$ ) ingredients in bubbles before visiting the museum, and a mean of 2.10 (S.D. $=0.90$ ) ingredients after visiting the museum.

\subsubsection{Order effects}

Based on the order of questions, no differences were found in the (1) children's mean correct response to the buoyancy questions, (2) children's skill level about why an object would sink or float, (3) how many ingredients of bubbles children listed, or (4) whether children could define a current.

\subsubsection{Gender effects}

There were no significant differences between girls and boys in children's (1) mean correct responses to whether objects would sink or float prior to participation in the combined museum and classroom lessons, (2) mean correct responses to whether objects would sink or float after participation in the combined museum and classroom lessons, (3) mean skill level prior to participation in the combined museum and classroom lessons, or (4) mean skill level after participation in the combined museum and classroom lessons. Furthermore, boys and girls did not differ in the number of correct bubble ingredients that they listed before or after participation in the museum and classroom lessons. Finally, there was no significant difference between girls and boys in their ability to define a current before or after participation in the combined museum and classroom lessons.

\subsection{Hypotheses testing}

Significant main effects and significant interaction effects pertinent to the hypotheses are described below. $\eta^{2}$ estimates of effect size are presented. $\eta^{2}$ is the measure of the proportion of variance accounted for by a predictor. When $\eta^{2}$ is 0.01 or above, it is considered a small effect size; when $\eta^{2}$ is 0.09 or above, it is considered a medium effect size; and when $\eta^{2}$ is 0.25 or above, it is considered a large effect size (Cohen, 1988).

\subsubsection{Buoyancy correctness of predictions}

The first hypothesis was that children would make more correct predictions about whether the objects would sink or float after visiting the science exhibits and participating in the science lessons compared to children assigned to other exhibits. To test this hypothesis, a one-way (science, non-science) ANCOVA 
with prior correct responses on the eight objects as a covariate was conducted. Classroom was a nested factor. Mean correct responses on the eight objects in the post-test served as the dependent variable. Contrary to the hypothesis, there was no effect for condition, $F(1,47)<1$. There was also no effect for classroom, $F(4,47)=1.30$, n.s. Children's prior correct responses was significantly associated with the children's correct answers after the museum visit and classroom lessons, $F(1,47)=5.78, P<$ $0.05, \eta^{2}=0.11$.

Additionally, a chi square test was conducted to examine if students were correct more often after visiting the science exhibits and participating in the science lessons compared to children assigned to other exhibits. No significant differences were found between the two groups, $\chi^{2}$ (d.f. $\left.=1, n=48\right)<1$.

\subsubsection{Buoyancy skill level}

The second hypotheses was that children who had visited the science exhibits and participated in the science lessons in their classrooms, would increase in their skill level relative to children who had visited other exhibits at the museum. To test this hypothesis, a one-way (science, non-science) ANCOVA with prior skill level as a covariate and classroom as a nested factor was conducted. Skill level in the post-test served as the dependent variable. In support of the hypothesis, children who visited science exhibits and participated in the science lessons $(M=1.94$, S.D. $=0.25)$ were scored at a higher level than children who visited other exhibits $(M=1.69$, S.D. $=0.64), F(1,47)=5.82, P<0.05, \eta^{2}=0.11$. Additionally, children's prior skill level was significantly associated with the children's skill level after the museum visit and classroom lessons, $F(1,47)=20.22, P<0.001, \eta^{2}=0.31$. Although classroom as a nested factor was significant, the significant differences were between the control classrooms rather than the intervention classrooms. Table 2 displays the mean skill level of children in the six classrooms before and after visiting the museum.

Additionally, a chi-square was conducted to test if children assigned to the science exhibits and science improved in their average skill level compared to children assigned to other exhibits. Children assigned to the science exhibits and lessons were more likely to increase in their skill level (20/30) than children assigned to other exhibits (3/18), $\chi^{2}($ d.f. $=1, n=48)=11.27, P<0.01$.

Table 2

Mean skill level across eight trials

\begin{tabular}{llr}
\hline Classroom & $\begin{array}{l}\text { Before museum visit } \\
\text { and classroom lessons }\end{array}$ & $\begin{array}{c}\text { After museum visit } \\
\text { and classroom lessons }\end{array}$ \\
\hline $\begin{array}{l}\text { Intervention classrooms } \\
1(n=8)\end{array}$ & $1.60(0.72)$ & $1.90(0.32)$ \\
$2(n=10)$ & $1.72(0.47)$ & $1.92(0.17)$ \\
$3(n=12)$ & $1.80(0.42)$ & $1.99(0.27)$ \\
Control classrooms & & $1.78(0.52)$ \\
$4(n=4)$ & $1.72(0.48)$ & $1.06(0.81)$ \\
$5(n=5)$ & $1.41(0.76)$ & $2.00(0.30)$ \\
$6(n=9)$ & $1.96(0.61)$ & \\
\hline
\end{tabular}

Note. Standard deviations are in parentheses. 


\subsubsection{Bubble ingredients}

The third hypothesis predicted that children who had visited the science exhibits and participated in the science lessons would list more correct ingredients in bubbles than would children who visited other exhibits. To test this hypothesis, a two-way (science, non-science) ANCOVA with prior number of ingredients listed served as a covariate was conducted. Number of correct ingredients in the post-test served as the dependent variable. As predicted, children who had visited the science exhibits and participated in the science lessons $(M=2.42$, S.D. $=0.76)$ listed more correct ingredients in bubbles than children who visited other exhibits $(M=1.56$, S.D. $=0.86), F(1,47)=14.40, P<0.001, \eta^{2}=0.24$.

\subsubsection{Definition of a current}

The fourth hypothesis predicted that children who visited the science exhibits and participated in the science lessons would be more likely to define a current compared to the children assigned to other exhibits. Before visiting the museum, no children from either group could define a current. As expected, children who were assigned to science were more likely to define a current than children not assigned to science, $\chi^{2}($ d.f. $=1, n=48)=7.58, P<0.01$. After the visit, 10 of the 30 children who were assigned to science could define a current. In comparison, none of the children assigned to the other exhibits could define a current after visiting the museum.

\subsubsection{Affective changes}

The fifth hypothesis was that children assigned to science would have more positive opinions about science after the museum visit than children not assigned to science. Prior to visiting the museum and engaging in science lessons, children assigned to science reported a mean of 2.62 (S.D. $=0.56$ ) out of a possible three in their liking of science compared to 2.67 (S.D. $=0.49$ ) reported by the children assigned to the other curriculums. After participation in the museum and classroom curriculum, children assigned to science reported a mean of $2.80($ S.D. $=0.41)$ in their liking of science compared to 2.78 (S.D. $=0.43$ ) for children assigned to the other curriculums. There was no significant difference between the two groups, $F(1,47)<1$. Additionally, children's reported opinions about science prior to the museum and classroom lessons was not significantly associated with their opinions after the museum and classroom lessons, $F(1,47)=1.53$, n.s.

Descriptive data suggest that across all the programs teachers believed that the program was worthwhile. Of the one hundred twenty teachers who answered a survey question regarding children's enjoyment at the museum, 111 reported the highest possible agreement (4 out of 4) that their students had fun while at the museum. The remaining nine teachers reported that they agreed that their students had fun ( 3 out of 4). Additionally, 109 of 123 teachers reported that the educational value of the museum program was of the high educational quality (4 out of 4) and the remaining 13 agreed that the educational quality was high (3 out of 4). In sum, teachers believed that the museum program was beneficial for their students.

\section{Discussion}

The results supported three of the five hypotheses. In general, children exhibited more content knowledge as well as more complex concepts. Specifically, children assigned to the integrated museum and classroom science curriculum were more likely than other children to express more correct knowledge about the content of bubbles and the definition of a current. They also indicated more complex concepts 
in their thinking about buoyancy (a skill). Children assigned to science verbalized more attributes in their justifications (e.g., the object is heavy, long, soft, etc.) of why objects sank or floated after participation in the program. Children assigned to the integrated science curriculum were not more likely than other children to make correct judgments about whether an object would sink or float. Finally, children assigned to the integrated curriculum did not increase in their reported enjoyment of science compared to other children, even though teachers reported that students enjoyed themselves while at the museum. The results are discussed in more detail below.

\subsection{Children's science learning}

Evidence of children's learning was assessed through their content knowledge and concept complexity before and after they experienced the integrated curriculum. Children's content knowledge increased about bubbles and currents, but not about whether objects would sink or float. Their concept complexity about buoyancy also indicated increases. Both content and concept skills are necessary for advanced science understanding. Children and adults need domain specific knowledge to reason more effectively (Bedard \& Chi, 1992); however, increased content knowledge alone is not sufficient to support mature reasoning strategies like hypothesis testing (Eylon \& Linn, 1988). Children with more domain knowledge and with more complex concepts are more likely to be able to set up experiments accurately and test their hypotheses (Linn, 1986).

The frequency of children's correct 'sink or float' judgments did not increase, whereas their concept complexity did. This discrepancy may be related to how difficult density is to understand. Prior research has found that even adults cannot perfectly judge whether an object will sink or float (Kohn, 1993). Similarly, Piaget (1960) suggested that it is not until formal operations that children truly differentiate weight and density. Increases in children's concept complexity may have been related to providing support at an appropriate level. As posited by socio-cultural theorists, meeting children at their zone of proximal development helps them increase their abilities (Rogoff, 1990; Vygotsky, 1978; Wertsch, 1991). Teachers who helped create the museum program tried to create a curriculum that met children at their zone of proximal development. Children's learning suggests that teachers and museum staff were able to do this successfully.

Another way that the museum docents may have supported children was by modeling appropriate strategies. Socio-cognitive theory suggests that children learn through observation and participation in activities (Bandura, 1997). Docents carefully guided children's predictions about how many marbles were needed to cause the bottles to sink. Indeed, science educators have found that making predictions aids in the understanding of science concepts (Linn \& Songer, 1987, as cited in Eylon \& Linn, 1988). Children's participation in determining how many marbles were needed for the bottle to sink gave them an opportunity to practice scientific experimentation.

The docents did not explain scientific concepts to children. Instead, they supported children in their development of explanations. Chapman (2000) suggests that supporting children in the development of their own explanatory models is better than providing them with explanations. Within the child development literature, question-asking is one type of teaching strategy that is believed to foster cognitive growth. According to Sigel (1982), questions are more likely than statements to encourage children to engage in active thinking and distancing skills. He hypothesizes that questions are cognitively demanding because they force the responder to reconstruct knowledge and thereby to become engaged in representational thought. Researchers have focused on the use of conceptual questions to help children learn distancing 
skills (McGillicuddy-DeLisi, 1988; Moreno, 1991; Sigel, 1982), which correlate with children's future success in mathematics and abstract reasoning (Sigel, Stinson, \& Flaugher, 1991). When children distance themselves, they engage in representational thought, which may be why the children who had visited the science exhibits demonstrated increases in their concept complexity or skill level.

Another reason that children may have increased in their skill level and improved their scientific vocabulary within the domain of science is that they conducted actual experiments. As Chapman (2000) argues, the best way for children to learn science and its corresponding vocabulary is to do science. He further posits that children need to observe scientific phenomenon. Moreover, actual experiments contribute to children's interest and motivation in science, which is a necessary precursor for conceptual change (Weaver, 1998). Although the experiments conducted within the museum with the help of the docents were simple, they were a beginning step in making students learn to test hypotheses, which has been suggested as a beginning step in learning to do everyday science (Crowley \& Galco, 2001).

Both correctness and concept complexity are valued in science education. While correctness did not improve in the context of this integrated curriculum, children's more complex concepts about buoyancy may later support them in acquiring more content knowledge and, thus, become more correct in their judgments.

\subsection{Affective learning}

Informal observations by both teachers and the first author suggest that the children enjoyed their visit to the museum. As seen in the field notes in the method section, children were very excited to be engaging in hands-on science while visiting the museum.

Despite such positive observations by the first author and the teachers' reports, children assigned to the integrated science curriculum did not report increased liking of science compared to children assigned to other areas. Why might this have occurred? Young children do not differentiate science from other school topics. Future research needs to find better quantitative methods of assessing children's enjoyment of hands-on science. In future studies of children's affect toward science, researcher should gauge the extent to which children know what science is. Another idea would be to ask children how much they like engaging in specific science-related activities (e.g., testing whether objects sink or float, observing chemical reactions, etc.) compared to activities in other domains (e.g., reading, coloring, etc.). Interest in science predicts science and math-related career selection for college-aged students (Hackett \& Betz, 1995). Given the disparity in the number of women and ethnic minorities involved in science (NSF, 2000), research must be conducted to find ways to increase children's enjoyment of science.

\subsection{Directions for future research}

For museum designers, this program suggests that children benefit from guided discovery while visiting a museum. Prior work has suggested that children do not make the appropriate comparisons when examining exhibits without the help of either computers (Gelman et al., 1991) or parents (Crowley \& Galco, 2001). Future research could test the amount of guidance necessary for young children to learn from visits to science museums. Another potential research direction would be to examine the effectiveness of having children generate their own explanations compared to providing simple explanations for the children. Some argue that children learn best when provided simple, developmentally appropriate explanations (e.g., Crowley \& Galco, 2001; Crowley \& Siegler, 1999) and analogies (Dunbar, 2000), whereas others 
posit that children must develop their own explanations (e.g., Chapman, 2000). Modifying the method of instruction provided by the museum docents would enable a direct test of these perspectives.

\subsection{Limitations}

One of the greatest limitations of this study is that it does not enable a test of whether the learning took place in the classroom, the museum, or a true combination of the two. However, the museum and school were more interested in finding the most effective way of educating the students. Thus, the researchers were bound by the constraints of this naturally occurring field experiment. Another limitation is that this study did not truly assess changes in children's reasoning abilities or deep conceptual knowledge. To truly induce conceptual change and influence underlying concepts would probably require a longer intervention period.

\subsection{Implications}

Using a hands-on, fun approach, the museum kindergarten partnership demonstrated an effective way of increasing young children's complexity skills and content knowledge of science. The gains are particularly impressive especially in light of the short duration of the program. As many suggest, children benefit from curriculum that makes connections outside of the classroom (Eylon \& Linn, 1988; Paris et al., 1998). Low-income children from ethnic minority backgrounds tend not to perform as well as their high-income and European-American peers on standardized science tests (NSF, 2000). As adults, they tend to be underrepresented in the science labor force (NSF, 2000). Given that curiosity and interest are predictors of continued science participation (Eylon \& Linn, 1988; Hackett \& Betz, 1995), programs such as this one may be able to keep underrepresented minorities interested and engaged in science.

\section{Acknowledgements}

This research was supported by grants from the Massachusetts Cultural Council, J. L. Hammett, and the Fund for Non-profits to the Boston Children's Museum. The authors would like to thank the following people for their help: Rachael Brown, Pat Kelliher, Mary Ann Martinelli, Sheila Ryan, and Ellen Tait. Additionally, the help of the kindergarten teachers and the museum program staff is very much appreciated. Finally, the authors would like to thank the reviewers for their helpful comments.

\section{References}

Atwater, M. M., Wiggins, J., \& Gardner, C. M. (1995). A study of urban middle school students with high and low attitudes toward science. Journal of Research in Science Teaching, 32, 665-677.

Baker, D., \& Learing, R. (1995). Letting girls speak out about science. Journal of Research in Science Teaching, 32 , 3-27.

Bandura, A. (1997). Self-efficacy: The exercise of control. New York: W. H. Freeman and Co.

Bedard, J., \& Chi, M. T. (1992). Expertise. Current Directions in Psychological Science, 1, 135-139.

Brown, A. L., Metz, K. E., \& Campione, J. C. (1996). Social interaction and individual understanding in a community of learners: The influence of Piaget and Vygotsky. In A. Tryphon \& J. Vonèche (Eds.), Piaget-Vygotsky: The social genesis of thought (pp. 145-170). East Sussex: Erlbaum. 
Chapman, O. L. (2000). Learning science involves language, experience, and modeling. Journal of Applied Developmental Psychology, 21, 97-108.

Cohen, J. (1988). Statistical power analysis for the social sciences (2nd ed.). Hillsdale, NJ: Erlbaum.

Crowley, K., \& Galco, J. (2001). Everyday activity and the development of scientific thinking. In K. Crowley, C. D. Schunn, \& T. Okada (Eds.), Designing for science: Implications from everyday, classroom, and professional settings. Mahwah, NJ: Erlbaum.

Crowley, K., \& Siegler, R. S. (1999). Explanation and generalization in young children's strategy learning. Child Development, 70, 304-316.

Dawson, T. (1999). 'A good education is ...' : A life-span investigation of developmental and conceptual features of evaluative reasoning about education. Dissertation Abstracts International, 60(3-B), (UMI No. 1329).

Dawson, T. (2002). A comparison of three developmental stage scoring systems. Journal of Applied Measurement, 3(2), $146-189$.

Dawson, T., \& Fischer, K. (2003). Hierarchical complexity scoring manual: Hierarchical complexity theory. Retrieved July 15, 2003, from http://gseacademic.harvard.edu/\%7Ehcs/base/HC.shtml.

Dawson, T., Xie, Y., \& Wilson, M. (2003). Domain-general and domain-specific developmental assessments: Do they measure the same thing? Cognitive Development, 18(1), 61-78.

Dunbar, K. (2000). How scientists think in the real world: Implications for science education. Journal of Applied Developmental Psychology, 21, 49-58.

Eylon, B., \& Linn, M. C. (1988). Learning and instruction: An examination of four research perspectives in science education. Review of Educational Research, 58, 251-301.

Fischer, K. W., \& Bidell, T. R. (1998). Dynamic development of psychological structures in action and thought. In R. M. Lerner (Ed.) \& W. Damon (Series Ed.), Handbook of child psychology (5th ed.). New York: Wiley.

Fischer, K. W., \& Granott, N. (1995). Beyond one-dimensional change: Parallel, concurrent, socially distributed processes in learning and development. Human Development, 38, 302-314.

Fleiss, J. L. (1981). Balanced incomplete block designs for inter-rater reliability studies. Applied Psychological Measurements, 5, 105-112.

Gelman, R., Massey, C. M., \& McManus, M. (1991). Characterizing supporting environments for cognitive development: Lessons from children in a museum. In L. B. Resnick, J. M. Levine, \& S. D. Teasley (Eds.), Perspectives on socially shared cognition (pp. 226-256). Washington, DC: American Psychological Association.

Hackett, G., \& Betz, N. E. (1995). Self-efficacy and career choice and development. In J. E. Maddux (Ed.), Self-efficacy, adaptation, and adjustment: Theory, research, and application (pp. 249-280). New York: Plenum Press.

Harbeman, M. (1991). The pedagogy of poverty versus good teaching. Phi Delta Kappan, 73, 290-294.

Hetherington, E., \& Parke, R. (1993). Child psychology: A contemporary viewpoint. New York: McGraw-Hill, Inc.

Inhelder, B., \& Piaget, J. (1958). The growth of logical thinking from childhood to adolescence (A. Parsons \& S. Seagrim, Trans.). New York: Basic Books (original work published in 1955).

Kohn, A. S. (1993). Preschoolers' reasoning about density: Will it float? Child Development, 46, 1637-1650.

Linn, M. (1986). Science. In R. Dillon \& R. J. Sternberg (Eds.), Cognition and instruction (pp. 155-204). New York: Academic Press.

Linn, M. C., \& Songer, N. B. (1987). Teaching a post-positive understanding of science: Incorporating technology into the curriculum. Berkeley: University of California (Computer as Lab Partner Project).

Marek, E., Boram, R., Laubach, T., \& Gerber, B. (2002). Conceptual understandings resulting from interactive science exhibits. Journal of Elementary Science Education, 14(2), 39-50.

Martinez, M. E. (1992). Interest enhancements to science experiments: Interactions with student gender. Journal of Research in Science Teaching, 29, 167-177.

Massachusetts Department of Education. (2001). Massachusetts science and technology/engineering curriculum framework. Retrieved July 15, 2003, from http://www.doe.mass.edu/frameworks/scitech/2001/0501.pdf.

McGillicuddy-DeLisi, A. V. (1988). Sex differences in parental teaching behaviors. Merrill-Palmer Quarterly, 34, $147-162$.

Meyerson, M. J., Ford, M. S., Jones, W. P., \& Ward, M. A. (1991). Science vocabulary knowledge of third and fifth grade students. Science Education, 75, 419-428.

Moreno, R. P. (1991). Maternal teaching of preschool children in minority and low-status families: A critical review. Early Childhood Research Quarterly, 6, 395-410.

National Science Foundation. (2000). Introduction: Representation in science and engineering. Retrieved July 21, 2003, from http://www.nsf.gov/sbe/srs/nsf99338/c1/c1s2.htm. 
Paris, S. G., Yambor, K. M., \& Packard, B. W. (1998). Hands-on biology: A museum-school-university partnership for enhancing students' interest and learning in science. The Elementary School Journal, 98, 267-289.

Piaget, J. (1960). The child's conception of physical causality. Ames, IA: Littlefield, Adams (original work published 1930).

Piaget, J. (1983). Piaget's theory. In P. H. Mussen (Series Ed.) \& W. Kessen (Vol. Ed.), Handbook of child psychology: vol. 1. History, theory and methods (4th ed.). New York: Wiley.

Ramey-Gassert, L., \& Walberg, H. (1994). Reexamining connections: Museums as science learning environments. Science Education, 78(4), 345-363.

Rogoff, B. (1990). Apprenticeship in thinking: Cognitive development in social context. New York: Oxford University Press.

Sigel, I. E. (1982). The relationship between parental distancing strategies and the child's cognitive behavior. In I. E. Sigel \& L. M. Laosa (Eds.), Families as learning environments for children (pp. 47-86). New York: Plenum Press.

Sigel, I. E., Stinson, E. T., \& Flaugher, J. (1991). Socialization of representational competence in the family. In L. Okagaki \& R. J. Sternberg (Eds.), Directors of development (pp. 121-141). Hillsdale, NJ: Lawrence Erlbaum Associates.

Smith, C., Carey, S., \& Wiser, M. (1985). On differentiation: A case study of the development of the concepts of size, weight, and density. Cognition, 21, 177-223.

Vygotsky, L. S. (1978). The development of higher psychological processes. Cambridge, MA: Harvard University Press.

Weaver, G. C. (1998). Strategies in K-12 science instruction to promote conceptual change. Science Education, 82, 455-472.

Welch, W., Walberg, H., \& Fraser, B. (1986). Predicting elementary science learning using national assessment data. Journal of Research in Science Teaching, 23(8), 699-706.

Wenner, G. (2003). Comparing poor, minority elementary students' interest and background in science with that of their White, affluent peers. Urban Education, 38, 153-172.

Wertsch, J. V. (1991). Voices of the mind: A sociocultural approach to mediated action. Cambridge, MA: Harvard University Press.

Yager, R. E., \& Yager, S. O. (1985). Changes in perceptions of science for third, seventh, and eleventh grade students. Journal of Research in Science Teaching, 22, 347-358. 